\title{
The effect of ankle tape on joint position sense after local muscle fatigue: a randomized controlled trial
}

\author{
Akram Jahjah ${ }^{\dagger}$, Dietmar Seidenspinner ${ }^{\dagger}$, Karl Schüttler, Antonio Klasan, Thomas J. Heyse, Dominik Malcherczyk \\ and Bilal Farouk El-Zayat
}

\begin{abstract}
Background: Ankle tape is widely used by athletes to prevent ankle sprain. Although there is growing evidence that ankle tape improve joint position sense, but yet it is not clear even if tape improve joint position sense after muscle fatigue, because fatigue impair joint position sense and raise the risk of ankle sprain. The aim of this study is to examine the effect of ankle tape on joint position sense after local muscle fatigue.

Method: This trial is a randomized controlled trial. 34 healthy subjects participated in this trial. Subjects were randomized distributed into two groups: with tape and without tape. Active and passive absolute error and variable error mean values for two target positions of the ankle joint $\left(15^{\circ}\right.$ inversions and inversion minus $5^{\circ}$ ) before and after fatigue protocol consisted of 30 consecutive maximal concentric/concentric contractions of the ankle evertors and invertors. In this trail joint position sense for all subjects was assessed using The Biodex System isokinetic dynamometer 3, this system is used also for fatigue protocol.

Results: For the variable error (VE), significant mean effect was found for active joint position sense in $15^{\circ}$ of inversion after muscle fatigue $(P<0,05)$. It was a significant decrease in the work in the last third of inversion detected $(P<0,05)$. There was no significant main effect found for fatigue index of eversion.

Conclusion: Ankle tape can improve joint position sense at the fatigue session when joint position sense becomes worse. As a result, ankle tape may be useful to prevent ankle sprain during playing sports. We suggest athletes and individuals at risk of ankle sprain to apply taping before high-load activity.
\end{abstract}

Trial registration: The study was retrospectively registered on the ISRCTN registry with study ID ISRCTN30042335 on 12th December 2017.

\section{Background}

Ankle tape is commonly used by athletes to prevent ankle sprain in sports [1]. Epidemiological studies have established the ability of tape to minimize the number of acute ankle sprains during a playing season. The main role of ankle taping is to limit movement in normal range [2]. Some authors have investigated the protective role of taping through proprioception and awareness of ankle position [3-9].

\footnotetext{
* Correspondence: elzayat@med.uni-marburg.de

${ }^{\dagger}$ Equal contributors

Center of Orthopedics and Traumatology, University Hospital Marburg, Baldingerstrasse, 35033 Marburg, Germany
}

Many risk factors have been reported in the literature for inversion ankle sprain, and are traditionally divided into intrinsic and extrinsic categories. Individual characteristic such as sex, weight, age, history of ankle sprain, joint laxity, functional instability, muscle strength, and proprioception are nominated as intrinsic factors. Outside effects such as quality of training, exercise load, play level, field conditions, shoe type, ankle bracing, and taping $[10,11]$.

Researchers have directly linked a fatigued state with impairment of joint position sense in either healthy or unhealthy individuals $[12,13]$. It has been assumed that neuromuscular feedback can be inhibited through muscle fatigue around the joint $[12,14]$. There is also growing 
evidence that fatigue influences the risk of inversion ankle sprains [15]. In support of fatigue as a risk factor, overall injury rates have been shown to increase towards the end of matches $[16,17]$. In addition, an epidemiologic study found that most ankle sprains occurred in the last third of the first and second halves of matches [17].

We examined the effect of ankle tape on joint position sense after local muscle fatigue. This effect has not been clearly delineated in the literature. Several authors have demonstrated this effect, but only at rest and not under local muscle fatigue conditions. Secondarily, we examined the influence of tape itself on local muscle fatigue.

\section{Methods}

\section{Subjects}

Thirty-four healthy subjects participated in this randomized controlled trial. Subjects with a history of lower extremity injuries, neurologic deficits, rheumatologic disease, and hypermobility were excluded. None of the subjects had experience with using ankle tape. All subjects were asked to refrain from any heavy exercise $48 \mathrm{~h}$ prior to the test protocol. All subjects were informed about the study details and possible side effects; written informed consent was obtained from all subjects prior to study participation and the study protocol was approved by the ethical committee of Philipps-University Marburg (Germany). Baseline data for physical characteristics were collected for each subject and included age, sex, height, weight, and leg dominance (Table 1).

Subjects were randomly distributed into control and intervention groups by block randomization using Random Allocation Software (2004) [9], which was implemented by two independent investigators. In both groups, joint position sense was measured before and after local muscle fatigue. Modified methods from previous study protocols were is used in this trial [18].

\section{Measurement of the joint position sense}

Joint position sense was assessed for all subjects using the Biodex System Isokinetic Dynamometer 3 and Biodex Advantage Software Package (Biodex Medical System Inc., Shirley, NY, USA). This instrument has been shown to be valid and reliable in prior publications [19]. Each subject was positioned barefoot in a beach chair position with the calf of the tested leg resting on the platform. Each foot was tightly secured to the dynamometer footplate with two straps to minimize movement between the sole of the foot and the footplate surface. The lower leg was also fixed to avoid knee movement. The tested extremity was in $45^{\circ}$ flexion. The dominant foot of the subject was aligned with the axis of the dynamometer and the ankle joint was fixed at $15^{\circ}$ of plantar flexion. Dynamometer and chair adjustments were made to align the midline of the knee. Active and passive joint position sense was tested in two positions: $15^{\circ}$ of inversion and inversion minus $5^{\circ}$. All subjects were blindfolded throughout the examination. The complete test protocol was implemented with each subject before the main test in order to minimize the learning effect.

For passive testing, the subject's foot was moved from the starting position minus $30^{\circ}$ to one of two randomly predetermined target positions, and held for $5 \mathrm{~s}$. Each subject was instructed to concentrate on the position of his or her foot. The foot was then passively returned to the starting position and started moving with a speed of $5 \%$ sy the Biodex System. The subject was instructed to push on a stop button when he or she thought the test position had been reached.

For active testing, we repeated the same method. As soon as the foot was passively returned to the starting position, subjects were asked to reproduce actively the target position and to push on a stop button when he or she reached the target.

We chose mid-range motion in inversion and eversion; otherwise subjects were able to return their foot more easily to the target position.

The absolute error (AE) is the difference in absolute value in degrees between chosen and target position, and is a measure of the overall accuracy of positioning. The variable error (VE) is the difference in real values between chosen and target position, and is a measure of the variability of positioning.

Accuracy of joint position sense is inversely proportional with $\mathrm{AE}$ and $\mathrm{VE}$ scores. The test was repeated three times to calculate the mean score used for analysis.

\section{Fatigue protocol}

Subjects were positioned on the chair with $30^{\circ}$ of seatback tilt. The ankle was placed at $15^{\circ}$ of plantar flexion. The knee of the tested ankle was placed at $45^{\circ}$ flexion. The chair was adjusted to keep the knee between the hip and the foot in the same midline. To limit extreme movements during the test, two straps were fixed around the pelvis and proximal to the knee. Subjects performed 10 repetitions of consecutive maximal concentric/concentric contractions of the ankle in order to become familiarized with the device and to minimize the restricted effect of the tape. They rested their foot for $10 \mathrm{~min}$ to recover muscle strength.

The local load applied to the ankle joint consisted of 30 consecutive maximal concentric/concentric contractions of the ankle evertors and invertors in the range of motion ROM ( $30^{\circ}$ of eversion and $30^{\circ}$ of inversion) at an angular velocity of $120^{\circ} / \mathrm{s}$. Subjects were verbally encouraged and motivated to work hard and perform at their maximum potential. Immediately after the fatigue protocol, joint position sense testing was initiated using the 
same methods as in the testing before fatigue, to minimize the effects related to recovery from fatigue.

Local fatigue was evaluated by measuring changes in fatigue index (\%), work (W) in Joules (J), work in the first third (W1), and work in the last third (W3). A fatigue index was adopted from Rebeiro et al. [20] and was calculated according following formula:

Fatigue index $=($ initial peak torque-final peak torque $)$

/initial peak torque $* 100$.

Initial peak torque and final peak torque were calculated as the average of the first and the last five repetition peak torques of the fatigue protocol. Thus, an increased fatigue index value represents an increased level of fatigue.

\section{Intervention}

Preventive taping for injuries to the lateral aspect of the ankle joint was used and applied according to Macdonald's method [21]. This works by supporting the lateral aspect of the ankle by mechanical support supplied by the tape and its interface with the anchors, and proprioceptive response triggered by the pull of the skin when moving the foot during activity. The material used for ankle taping was Leukotape ${ }^{\bullet}$ classic $(3.75 \mathrm{~cm}$, BSN medical GmbH, Hamburg, Germany) and $\mathrm{NOBA}^{\circledR}$-PRETAPE (10 cm, NOBAMED Paul Danz AG, Wetter/Ruhr, Germany).

\section{Statistical results}

Data analysis was performed using SPSS statistical software (version 17.0, SPSS Inc., Chicago, IL, USA). Using the primary question of the effect of the ankle tape on joint position sense before and after fatigue, active and passive joint position senses for two target positions of the ankle joint $\left(15^{\circ}\right.$ inversion and inversion minus $\left.5^{\circ}\right)$ were analysed individually using the paired $t$ test to evaluate the effects of fatigue on joint position sense with and without ankle tape. The independent $t$ test was used to compare differences between absolute error and variable error for the mean values of the two target positions. The secondary question was to determine the effects of ankle tape on fatigue. Therefore, the variables of fatigue index (FI), work (W), work at the first third (W1), and work at the last third (W3) were analysed in two directions, eversion and inversion, with and without ankle tape. The independent $t$ test was used to compare the differences among FI, W, W1, and W3 mean values for eversion and inversion between groups. A $p$-value of less than 0.05 was considered statistically significant.

\section{Results}

\section{Descriptive data}

Data analysis was performed using SPSS statistical software (version 17.0, SPSS Inc., Chicago, IL, USA). Using the primary question of the effect of the ankle tape on joint position sense before and after fatigue, active and passive joint position senses for two target positions of the ankle joint $\left(15^{\circ}\right.$ inversion and inversion minus $\left.5^{\circ}\right)$ were analysed individually using the paired $t$ test to evaluate the effects of fatigue on joint position sense with and without ankle tape. The independent $t$ test was used to compare differences between absolute error and variable error for the mean values of the two target positions. The secondary question was to determine the effects of ankle tape on fatigue. Therefore, the variables of fatigue index (FI), work (W), work at the first third (W1), and work at the last third (W3) were analysed in two directions, eversion and inversion, with and without ankle tape. The independent $\mathrm{t}$ test was used to compare the differences among FI, W, W1, and W3 mean values for eversion and inversion between groups. A $p$-value of less than 0.05 was considered statistically significant.

\section{Joint position sense}

For the variable error (VE), a significant mean effect was found for active joint position sense in $15^{\circ}$ of inversion after muscle fatigue $(p=0.034$, Table 2 , Fig. 1$)$. The subject's ability to perceive joint position sense for $15^{\circ}$ of inversion with ankle tape after muscle fatigue significantly improved; the mean error was $1.3^{\circ} \pm 5.7^{\circ}$ in the group without tape compared with the mean error of $0.2^{\circ} \pm 3.4^{\circ}$ in the group with tape. The mean absolute error (AE) before muscle fatigue for an active joint position sense in $15^{\circ}$ of inversion was $2.4^{\circ} \pm 2.7^{\circ}$ in the control group, versus $3.1^{\circ} \pm 2.1^{\circ}$ in the intervention group $(p=0.699)$. After muscle fatigue, the mean error for the same position in the intervention group was $2.5^{\circ}$ $\pm 2.3^{\circ}$ versus $4.8^{\circ} \pm 3.1^{\circ}$ in the control group. However, this difference was not found to be statistically significant ( $p=0.446$, Table 3, Fig. 2). No difference was found in absolute error for active joint position sense inversion minus $5^{\circ}$ before fatigue between the control and intervention groups $\left(2.4^{\circ} \pm 1.4^{\circ}\right.$ vs. $\left.2.3^{\circ} \pm 1.3^{\circ}, p=0.62\right)$; likewise, no difference was found between groups after fatigue $\left(3.1^{\circ} \pm 2.4^{\circ}\right.$ vs. $\left.1.9^{\circ} \pm 1.6^{\circ}, p=0.319\right)$.

Table 1 Subject characteristic in mean \pm SD

\begin{tabular}{llll}
\hline Variables & $\begin{array}{l}\text { Control } \\
\text { Group }(\mathrm{n}=17)\end{array}$ & $\begin{array}{l}\text { Intervention } \\
\text { Group }(\mathrm{n}=17)\end{array}$ & $\begin{array}{l}\text { All Subjects } \\
(\mathrm{n}=34)\end{array}$ \\
\hline Age (year) & $26,8 \pm 2,6$ & $26,7 \pm 3,7$ & $26,8 \pm 3,2$ \\
Height $(\mathrm{cm})$ & $173,1 \pm 9,7$ & $175,2 \pm 11,1$ & $174,1 \pm 10,3$ \\
Weight $(\mathrm{kg})$ & $68,7 \pm 17,2$ & $74,2 \pm 15,5$ & $71,5 \pm 16,4$ \\
\hline
\end{tabular}


Table 2 Effect of ankle tape on joint position sense variable error (VE) in degrees mean \pm SD

\begin{tabular}{|c|c|c|c|c|}
\hline & Variables & Control Group & Intervention Group & $P$ Value \\
\hline \multirow[t]{4}{*}{ Before Fatigue } & Active JPS inversion minus $5^{\circ}$ & $2,2 \pm 1,6$ & $2,2 \pm 1,4$ & 0,513 \\
\hline & Active JPS inversion $15^{\circ}$ & $0,6 \pm 3,6$ & $0,1 \pm 3,8$ & 0,562 \\
\hline & Passive JPS inversion minus $5^{\circ}$ & $2,4 \pm 1,7$ & $3,5 \pm 1,8$ & 0,686 \\
\hline & passive JPS inversion $15^{\circ}$ & $0,02 \pm 2,3$ & $-2 \pm 2,5$ & 0,381 \\
\hline \multirow[t]{4}{*}{ After Fatigue } & Active JPS inversion minus $5^{\circ}$ & $1,6 \pm 2,04$ & $2,4 \pm 3,2$ & 0,243 \\
\hline & Active JPS inversion $15^{\circ}$ & $1,3 \pm 5,7$ & $0,2 \pm 3,4$ & $0,034^{*}$ \\
\hline & Passive JPS inversion minus $5^{\circ}$ & $3,2 \pm 2,5$ & $3,4 \pm 1,6$ & 0,263 \\
\hline & passive JPS inversion $15^{\circ}$ & $-0,8 \pm 4,2$ & $-2,3 \pm 3,4$ & 0,379 \\
\hline
\end{tabular}

"Significant

\section{Muscle fatigue}

There was no significant effect found for the fatigue index of eversion $(19.6 \pm 18.2$ vs. $18.1 \pm 39.5, p=0.363)$ in the control vs. intervention groups (Table 4, Fig. 3). In inversion, there was no significant effect found for fatigue index, although the difference appears large $(24.6 \pm 16.4$ vs. $11.3 \pm 23.4, p=0.131$, Fig. 3 ). A significant decrease in work in the last third of inversion was detected ( $p=0.019$, Table 4, Fig. 4), showing that muscles fatigued faster in the group with tape than in the group without tape.

\section{Discussion}

To our knowledge, this study is the first to describe the effect of ankle tape on joint position sense after local muscle fatigue, and the first to describe the effect of ankle tape on muscle fatigue. The combination of these two issues may provide a better understanding of the influence that tape produces. We demonstrated that ankle tape improves joint position sense at an active $15^{\circ}$ of inversion after muscle fatigue.

An increase in fatigue index in the intervention group $(24.6 \% \pm 16.4)$ was observed compared to the control group $(11.3 \% \pm 23.4)$ in inversion. This result can be interpreted as evidence that taping provides support and limits functional motion, especially for inversion (Fig. 3). We also found a significant effect of ankle tape on the work in the last third of the fatigue protocol $(p=0.019)$ in inversion, but no significant effect in eversion ( $p=$ 0.756) (Table 4). Others reported that the use of tape limited inversion and maximized plantar flexion [22]. In this interpretation, tape affects the invertor muscle group, which was more fatigued in the intervention versus control group.

Evertor muscles have been shown to play an important role in preventing inversion ankle sprains [18] because of eccentric contractions that evert the ankle when it comes into inversion, before tissue strain becomes excessive [23]. This hypothesis seems to be acceptable because of the relationship between peroneal muscle weakness and chronically unstable ankles [24, 25]. Most authors confirmed the role of evertor muscles in preventing ankle sprain [18], finding no relationship between invertor muscle strength and ankle sprains. These findings, in combination with presented results indicate that the fatigue of invertor muscles have no direct influence on ankle sprain.

The results of this trial are comparable to that of Robbins et al. [3] and Miralles et al. [22]; however, these two studies investigated the effect of tape on joint position sense in ankle plantar flexion and dorsiflexion, while this trial tested joint position sense in ankle inversion and eversion. In 1995, Robbins et al. were the first to study

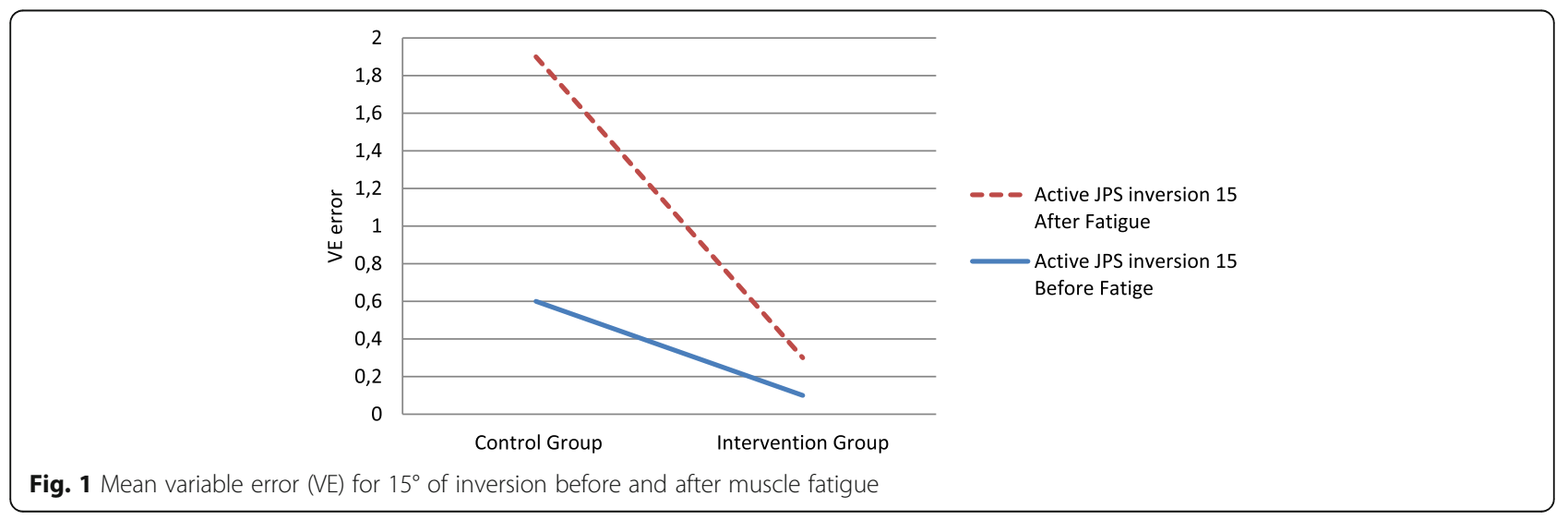


Table 3 Effect of ankle tape on joint position sense absolute error (AE) in degrees mean \pm SD

\begin{tabular}{|c|c|c|c|c|}
\hline & Variables & Control Group & Intervention Group & $P$ Value \\
\hline \multirow[t]{4}{*}{ Before Fatigue } & Active JPS inversion minus $5^{\circ}$ & $2,4 \pm 1,4$ & $2,3 \pm 1,3$ & 0,62 \\
\hline & Active JPS inversion $15^{\circ}$ & $2,4 \pm 2,7$ & $3,1 \pm 2,1$ & 0,699 \\
\hline & Passive JPS inversion minus $5^{\circ}$ & $2,4 \pm 1,7$ & $3,6 \pm 1,7$ & 0,558 \\
\hline & Passive JPS inversion $15^{\circ}$ & $1,5 \pm 1,7$ & $2,6 \pm 1,8$ & 0,542 \\
\hline \multirow[t]{4}{*}{ After Fatigue } & Active JPS inversion minus $5^{\circ}$ & $1,9 \pm 1,6$ & $3,1 \pm 2,4$ & 0,319 \\
\hline & Active JPS inversion $15^{\circ}$ & $4,8 \pm 3,1$ & $2,5 \pm 2,3$ & 0,446 \\
\hline & Passive JPS inversion minus $5^{\circ}$ & $3,3 \pm 2,4$ & $3,4 \pm 1,6$ & 0,297 \\
\hline & Passive JPS inversion $15^{\circ}$ & $3,3 \pm 2,6$ & $3,7 \pm 1,7$ & 0,287 \\
\hline
\end{tabular}

the effect of ankle tape on foot position awareness before and after exercise. They significant improvement of position sense in absolute error in ankles taped before and after exercise, specifically in an exercise protocol that consisted of $30 \mathrm{~min}$ of running and playing basketball. They compared two groups wearing tape and athletic footwear. Their results indicate that taping influenced foot position awareness mainly when the surface slope was greater than $10^{\circ}$ plantar flexion, which is probably most relevant to ankle sprains. These results reinforce our findings that the effect of tape is greater when there is a larger range of motion; in this trial, there was a greater effect in $15^{\circ}$ of inversion compared to inversion minus $5^{\circ}$. This may be more relevant to ankle sprain, because lateral ankle sprain occurs most frequently when there is a large range of inversion.

Miralles et al. studied the effect of tape on joint position sense, before the tape was placed compared with placement after $48 \mathrm{~h}$. The intervention group showed a trend towards improvement after $48 \mathrm{~h}$ for all positions compared to the control group. This improvement was significant in dorsiflexion and in the neutral position. In contrast to Robbins's findings, that proprioception was present mainly in ranges of movement over $10^{\circ}$; Miralles's results indicate that joint position sense may improve even for positions under $10^{\circ}$. The results of this study reinforce Robbins's, as this effect is reported in $15^{\circ}$ of inversion.

Muscle fatigue protocols can be divided into three main categories: muscle fatigue over time [26], fatigue due to the number of repetitions [20], and fatigue due to the intensity of peak torque [15]. In this trial, muscle fatigue was based on the number of repetitions of eversion and inversion at the ankle joint. Through isometric contraction, subjects do not move the foot; it stays in the neutral position. Thus, it is not possible to notice the effect of tape on muscle fatigue. Also, if all subjects have a maximum voluntary contraction MVC equal to $50 \%$, it would not be possible to compare muscle fatigue results since all subjects would have the same level of fatigue.

These results showed an alteration of joint position sense in $\mathrm{AE}$ in the control group after muscle fatigue. This was in an active $15^{\circ}$ of inversion before $\left(2.4^{\circ} \pm\right.$ $\left.2.7^{\circ}\right)$ and after fatigue $\left(4.8^{\circ} \pm 3.1^{\circ}\right)$ (Table 3$)$. These results support the findings of other researchers, such as Mohammadi et al. [15], who investigated the effect of fatigue due to contraction of evertor muscles on joint position sense in male soccer players. They reported that joint position sense in $\mathrm{AE}$ in active $15^{\circ}$ of inversion was $1.9^{\circ} \pm 1.2^{\circ}$ before fatigue and $3.2^{\circ} \pm 1.9^{\circ}$ after fatigue. They also reported this difference in inversion minus $5^{\circ}$, which was $1.7^{\circ} \pm 0.7^{\circ}$ before fatigue

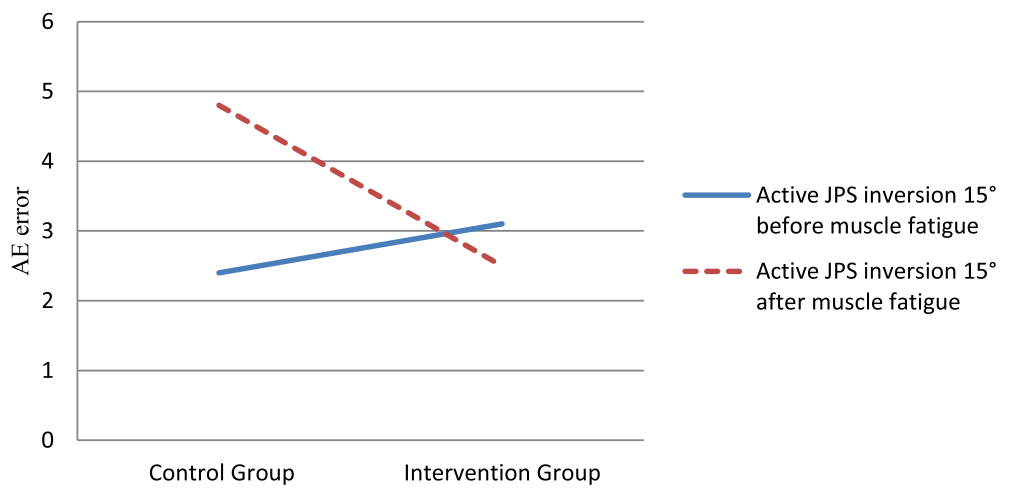

Fig. 2 Mean absolute error (AE) for $15^{\circ}$ of inversion before and after muscle fatigue 
Table 4 Effect of ankle tape on muscle fatigue \pm SD

\begin{tabular}{lllll}
\hline & Variables & Control Group & Intervention Group & $P$ Value \\
\hline Eversion & Fatigue Index & $19,6 \pm 18,2$ & $18,1 \pm 39,5$ & 0,363 \\
& Work & $307,3 \pm 98,7$ & $327,5 \pm 101,8$ & 0,768 \\
& Work 1_Third & $112,4 \pm 37,9$ & $120,3 \pm 42,9$ & 0,653 \\
& Work3_Third & $87,4 \pm 30,7$ & $93 \pm 28,6$ & 0,756 \\
Inversion & Fatigue Index & $11,3 \pm 23,4$ & $24,6 \pm 16,4$ & 0,131 \\
& Work & $319,1 \pm 88,6$ & $327,3 \pm 126,6$ & 0,166 \\
& Work 1_Third & $113,9 \pm 49,4$ & $122,9 \pm 49,4$ & 0,252 \\
& Work3_Third & $94,4 \pm 23,4$ & $87,2 \pm 40,3$ & $0,019^{*}$ \\
\hline
\end{tabular}

"Significant

and $2.9^{\circ} \pm 1.3^{\circ}$ after fatigue; this is in contrast to our presented results in this position. Forestier et al. [12] investigated how an isometric exhaustion test affects position sense at the ankle using a matching task. In their trial, joint position sense in dorsiflexion and plantar flexion were measured. The results showed an alteration of joint position sense after fatigue: in $\mathrm{AE}$ it was $2.2^{\circ} \pm 1.3^{\circ}$ before fatigue and $3.2^{\circ} \pm 1.8^{\circ}$ after fatigue. These results also support the findings of this trial.

Several mechanisms are involved in how fatigue may influence joint position sense. It has been suggested that increased joint laxity may play a role in joint position sense changes after fatigue, because fatigue increases laxity of ankle joint ligaments [27]. A further possible mechanism may be the effect of fatigue on peripheral receptors. The relative contribution of joint and muscle receptors to measure joint position sense deficits after a fatigue protocol also remains controversial. It is generally accepted that the greatest contribution to position sense is from muscular receptors [28, 29]. Several reports have claimed that fatigue presumably affects muscle receptors more than joint receptors; this means that a decrease in joint position sense may be due to loss of muscle receptor input [30-32].

These two mechanisms are important for the interpretation of mentioned results, which demonstrate that tape improves joint position sense after local fatigue and these mechanisms actually respond to the mechanisms suggestive of the effect of fatigue on joint position sense. The first mechanism is the mechanical role of tape in limiting the range of motion, which can minimize joint laxity after muscle fatigue. This effect can improve joint position sense [4]. The second mechanism is to improve muscles receptors, which are impaired after muscle fatigue and can thus improve joint position sense after fatigue [33].

\section{Limitations}

Taping by all subjects is not $100 \%$ reliable because it has been applied by humans, and it is related to the type of foot, skin, and tape. Further, the foot was tightly secured to the dynamometer footplate with two straps; the straps might have affected the results because they play the role of another external support to the foot.

\section{Recommendations}

More research is required to investigate the effect of tape on other groups of professional athletes, such as basketball or football players. Limiting the sample population to males or females may also be beneficial due to sex differences in laxity and muscle strength. Reliability and validity of this fatigue protocol need further investigation, by assessing $\mathrm{MVC}$ before and after taping. Epidemiological studies are needed to define the preventive role of tape in injuries of the ankle joint.

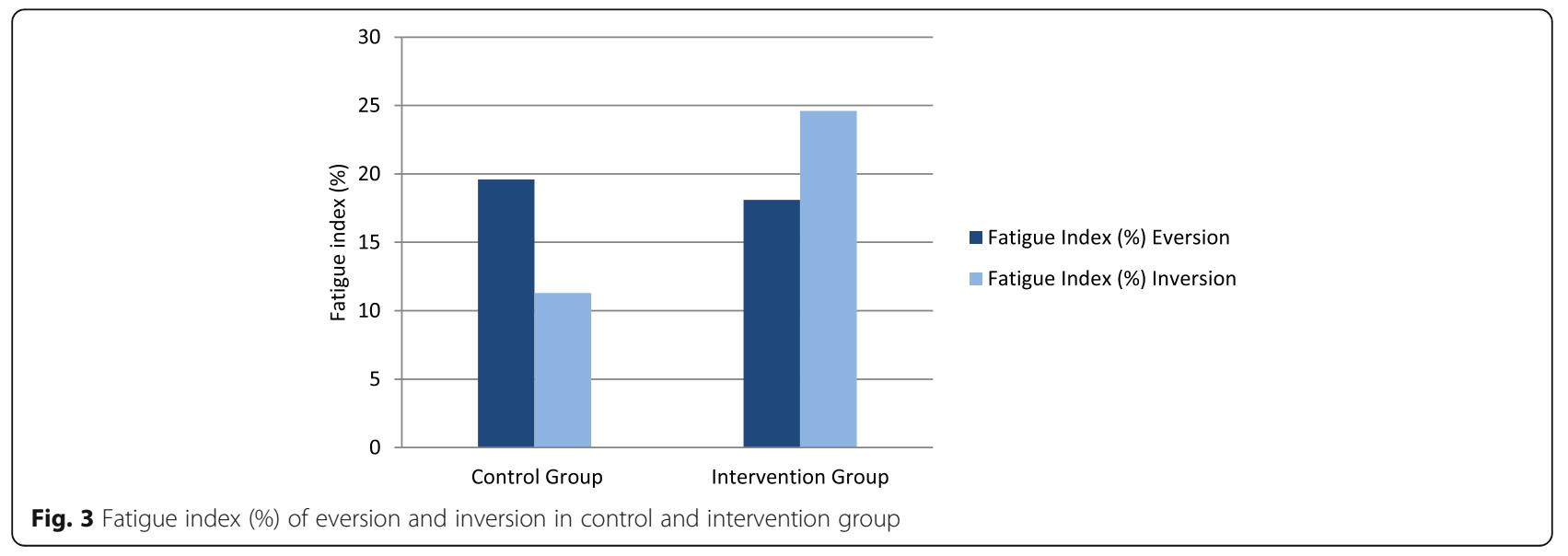




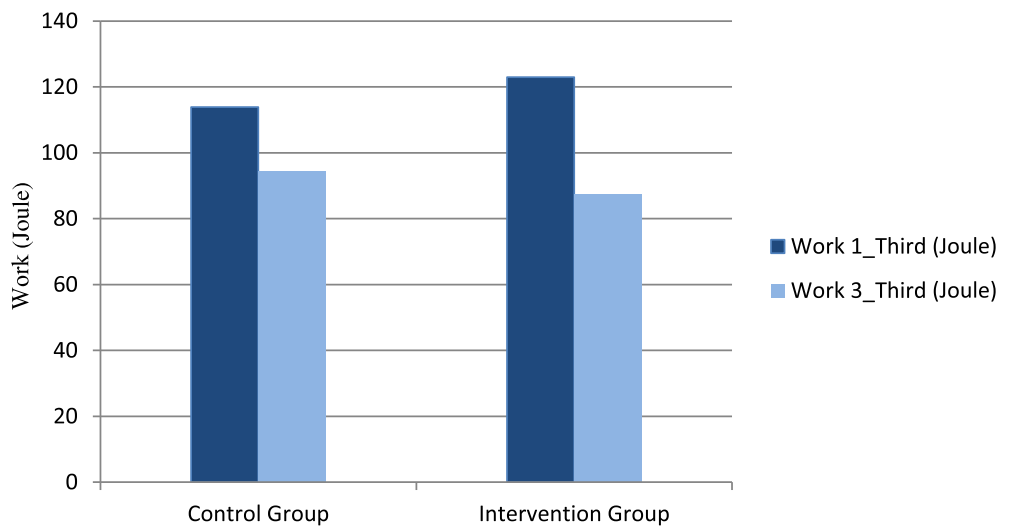

Fig. 4 Work in the first and the last third of muscle fatigue protocol, the difference of work at the last session between control and intervention group was significant $(P<0.05)$

\section{Conclusions}

In conclusion, we demonstrated that joint position sense significantly improves after taping of the ankle joint in $15^{\circ}$ of inversion after local muscle fatigue. In addition, we proved that tape fatigues the ankle in the direction of inversion. These results show that ankle tape can improve joint position sense at the fatigue session, when joint position sense becomes less acute. Thus, ankle tape may be useful before high intensity-demanding functional activity.

\section{Abbreviations}

AE: Absolute error; Fl: Fatigue Index; MVC: Maximum voluntary contraction; ROM: Range of motion; VE: Variable error; W: Work

\section{Acknowledgements}

The authors wish to thank the Department of Physiotherapy of the PhilippsUniversity Marburg, Germany for support in the laboratory facilities.

\section{Funding}

There was no external funding or sponsoring in this study.

The material costs were funded through the Department of Orthopedics and Rheumatology, University Hospital Marburg, Germany. The laboratory facilities are owned by the Orthopedics and Rheumatology, University Hospital Marburg, Germany.

\section{Availability of data and materials}

The datasets used and/or analyzed during the current study are available from the corresponding author on reasonable request.

\section{Authors' contributions}

All authors have read and approved the final manuscript. BFE participated in the study design, carried out the study, interpreted the results, and drafted the manuscript. TH, AK, DM and KS helped with the draft of the manuscript and critical revision as well as interpretation of the results. DS set up the protocol, carried out the study and participated in interpretation of the results, performed the statistical data analysis as well as supported in the draft of the manuscript. AJ participated in the design of the study, carried out the study, interpreted the results, and helped with the draft of the manuscript.

\section{Ethics approval and consent to participate}

The study protocol was approved by the ethical committee of the faculty of medicine of the Philipps-University Marburg (Germany).The reference number is 23/12. Written informed consent was obtained from all subjects prior to study participation.
Consent for publication

Not applicable

\section{Competing interests}

The authors declare that they have no competing interests' in relation to this study.

\section{Publisher's Note}

Springer Nature remains neutral with regard to jurisdictional claims in published maps and institutional affiliations.

Received: 29 March 2017 Accepted: 13 December 2017

Published online: 09 January 2018

\section{References}

1. Dizon JM, Reyes JJ. A systematic review on the effectiveness of external ankle supports in the prevention of inversion ankle sprains among elite and recreational players. J Sci Med Sport. 2010;13(3):309-17.

2. Laughman RK, et al. Three-dimensional kinematics of the taped ankle before and after exercise. Am J Sports Med. 1980;8(6):425-31.

3. Robbins S, Waked E, Rappel R. Ankle taping improves proprioception before and after exercise in young men. Br J Sports Med. 1995;29(4):242-7.

4. Karlsson J, Andreasson GO. The effect of external ankle support in chronic lateral ankle joint instability. An electromyographic study. Am J Sports Med. 1992;20(3):257-61.

5. Forbes $\mathrm{H}$, et al. The effect of prophylactic ankle support during simulated soccer activity. J Sport Rehabil. 2013;22(3):170-6.

6. Jerosch J, et al. The influence of orthoses on the proprioception of the ankle joint. Knee Surg Sports Traumatol Arthrosc. 1995;3(1):39-46.

7. Lentell $\mathrm{G}$, et al. The contributions of proprioceptive deficits, muscle function, and anatomic laxity to functional instability of the ankle. J Orthop Sports Phys Ther. 1995:21(4):206-15.

8. Hamill J, et al. Evaluation of two ankle appliances using ground reaction force data. J Orthop Sports Phys Ther. 1986;7(5):244-9.

9. Saghaei, M. Random allocation software. 2004; Available from: http:// mahmoodsaghaei.tripod.com/Softwares/randalloc.html.

10. Willems TM, et al. Intrinsic risk factors for inversion ankle sprains in femalesa prospective study. Scand J Med Sci Sports. 2005;15(5):336-45.

11. Beynnon BD, Murphy DF, Alosa DM. Predictive factors for lateral ankle sprains: a literature review. J Athl Train. 2002:37(4):376-80.

12. Forestier $\mathrm{N}$, Teasdale $\mathrm{N}$, Nougier $\mathrm{V}$. Alteration of the position sense at the ankle induced by muscular fatigue in humans. Med Sci Sports Exerc. 2002; 34(1):117-22.

13. Myers JB, et al. Proprioception and neuromuscular control of the shoulder after muscle fatigue. J Athl Train. 1999:34(4):362-7.

14. Johnston RB 3rd, et al. Effect of lower extremity muscular fatigue on motor control performance. Med Sci Sports Exerc. 1998;30(12):1703-7. 
15. Mohammadi F, Roozdar A. Effects of fatigue due to contraction of evertor muscles on the ankle joint position sense in male soccer players. Am J Sports Med. 2010;38(4):824-8.

16. Gabbett TJ. Incidence, site, and nature of injuries in amateur rugby league over three consecutive seasons. Br J Sports Med. 2000;34(2):98-103.

17. Woods $C$, et al. The football association medical research Programme: an audit of injuries in professional football: an analysis of ankle sprains. $\mathrm{Br} \mathrm{J}$ Sports Med. 2003;37(3):233-8.

18. Willems T, et al. Proprioception and muscle strength in subjects with a history of ankle sprains and chronic instability. J Athl Train. 2002;37(4):487-93.

19. Drouin JM, et al. Reliability and validity of the Biodex system 3 pro isokinetic dynamometer velocity, torque and position measurements. Eur J Appl Physiol. 2004;91(1):22-9.

20. Ribeiro F, Mota J, Oliveira J. Effect of exercise-induced fatigue on position sense of the knee in the elderly. Eur J Appl Physiol. 2007;99(4):379-85.

21. Macdonalds R, editor. Pocketbook of taping techniques. London: Elsevier; 2012.

22. Miralles I, et al. Ankle taping can improve proprioception in healthy volunteers. Foot Ankle Int. 2010;31(12):1099-106.

23. Wilson EL, Madigan ML. Effects of fatigue and gender on peroneal reflexes elicited by sudden ankle inversion. J Electromyogr Kinesiol. 2007;17(2):160-6.

24. Hartsell HD, Spaulding SJ. Eccentric/concentric ratios at selected velocities for the invertor and evertor muscles of the chronically unstable ankle. $\mathrm{Br} J$ Sports Med. 1999;33(4):255-8.

25. Staples OS. Result study of ruptures of lateral ligaments of the ankle. Clin Orthop Relat Res. 1972:85:50-8.

26. Miura K, et al. The effect of local and general fatigue on knee proprioception. Arthroscopy. 2004;20(4):414-8.

27. Nawata $K$, et al. Anterior-posterior knee laxity increased by exercise. Quantitative evaluation of physiologic changes. Acta Orthop Scand. 1999; 70(3):261-4.

28. Gandevia SC. Neural control in human muscle fatigue: changes in muscle afferents, motoneurones and motor cortical drive [corrected]. Acta Physiol Scand. 1998;162(3):275-83

29. Lattanzio PJ, Petrella RJ. Knee proprioception: a review of mechanisms, measurements, and implications of muscular fatigue. Orthopedics. 1998; 21(4):463-70. discussion 470-1; passim

30. Hiemstra LA, Lo IK, Fowler PJ. Effect of fatigue on knee proprioception: implications for dynamic stabilization. J Orthop Sports Phys Ther. 2001; 31(10):598-605.

31. Nyland JA, et al. Relationship of fatigued run and rapid stop to ground reaction forces, lower extremity kinematics, and muscle activation. J Orthop Sports Phys Ther. 1994;20(3):132-7.

32. Sharpe $\mathrm{MH}$, Miles TS. Position sense at the elbow after fatiguing contractions. Exp Brain Res. 1993;94(1):179-82.

33. Simoneau GG, et al. Changes in ankle joint proprioception resulting from strips of athletic tape applied over the skin. J Athl Train. 1997;32(2):141-7.

\section{Submit your next manuscript to BioMed Central and we will help you at every step:}

- We accept pre-submission inquiries

- Our selector tool helps you to find the most relevant journal

- We provide round the clock customer support

- Convenient online submission

- Thorough peer review

- Inclusion in PubMed and all major indexing services

- Maximum visibility for your research

Submit your manuscript at www.biomedcentral.com/submit 